\title{
Social Ontology: Some Basic Principles ${ }^{1}$
}

\author{
John R. Searle
}

University of California (Berkeley). Department of Philosophy

searle@cogsci.berkeley.edu

\begin{abstract}
The aim of this article is to explore the problem of social ontology, by developing the argument presented in The Construction of Social Reality (1995). After some preliminary distinctions (section 1), the article describes the logical structure of society using three concepts: collective intentionality, the assignment of function, and constitutive rules and procedures (section 2). Some further developments of this approach are presented: the analysis of status indicators, and the case of institutions where there is a status function but no physical object on which it is imposed (section 3). Some remarks are also made about the taxonomy of institutional facts (section 4), about the relationship between conceptual analysis and empirical data (section 5), and, finally, about the concept of institutional facts (section 6).
\end{abstract}

Key words: social ontology, institutional facts, collective intentionality, constitutive rules, assignment of function.

\section{Resumen. Ontología social: algunos principios básicos}

El objetivo de este artículo es explorar el problema de la ontología social, desarrollando el argumento presentado en La construcción de la realidad social (1995). Después de hacer algunas distinciones preliminares (sección 1), el artículo describe la estructura lógica de la sociedad usando tres conceptos: intencionalidad colectiva, asignación de función, y reglas y procedimientos constitutivos (sección 2). Se presentan algunos desarrollos posteriores de este enfoque: el análisis de indicadores de status, y el caso de las instituciones donde existe una función de status pero no un objeto físico sobre el que la misma se impone (sección 3). Se hacen también algunas observaciones sobre la taxonomía de los hechos institucionales (sección 4), sobre la relación entre el análisis conceptual y los datos empíricos (sección 5), y, finalmente, sobre el concepto de hechos institucionales (sección 6).

Palabras clave: ontología social, hechos institucionales, intencionalidad colectiva, reglas constitutivas, asignación de función.

1. I am indebted to a rather large number of people for discussion of the matters in this article. I cannot thank all of them, but I do especially want to thank, Josef Moural, Barry Smith, and especially my wife, Dagmar Searle. Special thanks also to Roy d'Andrade, who read the first draft and made helpful comments. 


\section{Contents}

I. The Problem of Social Ontology

II. The Logical Structure of Society III. Further Developments in the Theory of Social Ontology

IV. How Many Kinds of Institutional
V. Conceptual Analysis and Empirical Data

VI. Different Kinds of «Institutions»

References

Facts Are There?

\section{The Problem of Social Ontology}

The aim of this article is to explore the problem of social ontology. The form that the exploration will take is a development of the argument that I presented in The Construction of Social Reality ${ }^{2}$. I will summarize some of the results of that book and then develop the ideas further.

First of all, why is there a problem about social ontology at all? We are talking about the mode of existence of social objects such as the United States of America, the San Francisco Forty Niners football team, the University of California and the Squaw Valley Property Owners Association, as well as such large-scale institutions as money or private property. We are also talking about social facts, such as the fact that I am a citizen of the United States, that the piece of paper that I hold in my hand is a twenty dollar bill, and that France is a member of the European Union. We are also talking about social processes and events, such as the current presidential election campaign, the collapse of communism and the last World Series. We are talking, in short, about social facts, social objects, and social processes and events. To repeat the question, why is there a problem about these phenomena?

The problem arises in various forms, but one is this: We know independently that the world consists entirely of physical particles in fields of force (or whatever the ultimately correct physics tells us are the final building blocks of matter) and that these physical particles are organized into systems and that some of the carbon-based systems have evolved over a period of about five billion years into a very large number of animal and plant species, among which, we humans are one of the species capable of consciousness and intentionality. Our question, in its most broad and naïve form is: How can such animals as ourselves create a «social» reality? How can they create a reality of money, property, government, marriage and, perhaps most important of all, language? A peculiarly puzzling feature of social reality is that it exists only because we think it exists. It is an objective fact that the piece of paper in my hand is a twenty dollar bill, or that I am a citizen of the United States, or that the Giants beat the Athletics 3-2 in yesterday's baseball game. These are all objective facts in the sense that they are not matters of my opinion. If I believe the contrary, 
I am simply mistaken. But these objective facts only exist in virtue of collective acceptance or recognition or acknowledgement. What does that mean? What does "collective acceptance or recognition or acknowledgement" amount to?

An absolutely fundamental distinction we need to make before we can even begin to discuss these issues is that between those features of reality that exist independently of us, features I will call observer-independent, and those features that depend on us for their existence, which I will call observer-relative. Examples of observer-independent phenomena are force, mass, gravitational attraction, the chemical bond, photosynthesis, the solar system and tectonic plates. Examples of observer dependent facts are the sorts of examples I mentioned earlier, such as that I am a citizen of the United States, that baseball is a game played with nine men on a side, and that the United States of America contains fifty states. Roughly speaking, we can say that the social sciences are about observer relative facts; the natural sciences are about observer independent facts. A simple rough-and-ready test for whether or not a fact is observer independent is this: Could it have existed if there had been no conscious agents at all? If the fact could have existed even if there had never been any human beings or other conscious agents, for example, the fact that there is gravitational attraction between the earth and the moon, then the fact is observer independent. If, however, the fact requires conscious agents for its very existence in the way that facts about money, property, government and marriage require conscious agents, then the fact is at least a candidate for being observer relative. I said this was only a rough-and-ready test. The reason it is not sufficient as it stands is that the existence of consciousness and intentionality, on which observer dependent facts rest for their very existence, are themselves observer independent phenomena. The fact that the piece of paper in front of me is a twenty dollar bill is observer relative; that fact exists only relative to the attitudes of the participants in the activities of buying, selling, etc. But the attitudes that those people have are not themselves observer relative. They are observer independent.

I think it is worth going through this matter carefully. The piece of paper in my hand is a twenty dollar bill. What fact about it makes it a twenty dollar bill? Its physics and chemistry are not enough. If we wanted to go into detail, a complex legal story would have to be told about the U.S government, the Dept of the Treasury and the Bureau of Engraving and Printing. But a crucial element of the story is the attitudes of the people involved. To put the matter crudely, a necessary condition of its being money is that people have to intend it to be, and think it is money. So its existence as money is observer relative. But what about the attitudes? Suppose I now think, «This is a twenty dollar bill». That attitude and countless others like it are constitutive of the observer relative fact that things of this sort are money. But the attitudes of the observers are not themselves observer relative. I can think that it is money regardless of whether others think that I think that it is money. So the observer relative existence of social phenomena is created by a set of observer independent mental phenomena, and our task is to explain the nature of that creation. 
You might think that these issues would long ago have been resolved because we have, after all, a rather long tradition of discussion of foundational issues in the social sciences, and we are, of course, much indebted to the great founders of the social sciences such as Max Weber, Georg Simmel, Emile Durkheim, and Alfred Schütz. Before them we had such great philosophers as David Hume, Jean Jacques Rousseau, and Adam Smith —one could continue the list back to Aristotle's Politics. What can we add to this great tradition? There is a serious weakness in all of the classical discussions of the existence of social reality: all of the thinkers I have mentioned took language for granted. Weber, Schütz, Simmel and Durkheim all presuppose the existence of language and then, given language, ask about the nature of society. And they are in very good company because the tendency to presuppose language when discussing the foundations of society goes back to Aristotle. It is, for example, an amazing fact about the social contract theorists that they presupposed a community of humans who had a language and who then got together to make an original contract which founded society. I would want to say, if you share a common language and are already involved in conversations in that common language, you already have a social contract. The standard account that presupposes language, and then tries to explain society, has things back to front. You cannot begin to understand what is special about human society, how it differs from primate societies and other animal societies, unless you first understand some special features of human language. Language is the presupposition of the existence of other social institutions in a way that they are not the presupposition of language. This point can be stated precisely. Institutions such as money, property, government and marriage cannot exist without language, but language can exist without them. Now one might feel that we have overcome this lacuna in the twentieth century as various sociological theorists have been sensitive to the problem of language. In addition to a rich tradition of linguistic anthropology, we have the recent writings of sociological theorists, especially Bourdieu and Habermas, and perhaps Foucault as well. But I am afraid even they take language for granted. Bourdieu, following Foucault, states correctly that people who are capable of controlling the linguistic categorizations that are common in a society have a great deal of power in that society, and Habermas emphasizes the importance of speech acts and human communication in producing social cohesion. But, again, all three fail to see the essentially constitutive role of language. Language does not function just to categorize and thus give us power, à la Bourdieu, and it does not function just, or even primarily, to enable us to reach rational agreement à la Habermas. It has much more basic and fundamental functions which I will get to in a few moments.

One last distinction before we go to work. Our culture makes a great deal of the distinction between objectivity and subjectivity, but this distinction is systematically ambiguous between an epistemic sense and an ontological sense. If I say, «Rembrandt was born in 1606,» that statement is epistemically objective. It can be ascertained as true or false independent of the attitudes of 
observers. But if I say, «Rembrandt was a better painter than Rubens,» that statement is, as they say, "a matter of opinion.» It is «subjective». But in addition to the distinction between epistemic objectivity and subjectivity - and in a way the foundation of the distinction of epistemic subjectivity and objectivity - is an ontological distinction between ontological subjectivity and ontological objectivity. Mountains, molecules, and tectonic plates have an existence that is independent of the attitudes and feelings of observers. But pains, tickles, itches, emotions and thoughts have a mode of existence which is ontologically subjective in the sense that they only exist insofar as they are experienced by human or animal subjects. Now, the importance of this distinction for our discussion is this: The fact, for example, that George W. Bush is president of the United States; and the fact that, for example, the piece of paper I have in my hand is a twenty dollar bill are epistemically objective facts. But the important thing to emphasize is that such social institutional facts can be epistemically objective even though human attitudes are part of their mode of existence. That is, observer relativity implies ontological subjectivity but ontological subjectivity does not preclude epistemic objectivity. We can have epistemically objective knowledge about money and elections even though the kinds of facts about which one has epistemically objective knowledge are themselves all ontologically subjective, at least to a degree which we need to specify.

So let us just summarize where we are right now. We need the distinction between observer relative and observer independent facts. We also need a distinction between epistemic objectivity and subjectivity on the one hand and ontological objectivity and subjectivity on the other hand. Most of the phenomena that we are discussing, such phenomena as money, governments, and football games, are observer relative. But at the same time, they contain components of observer independent but ontologically subjective human attitudes. Though the constitution of society thus contains ontologically subjective elements as absolutely essential to its existence, all the same the ontological subjectivity of the domain does not prevent us from getting an epistemically objective account of the domain. In a word, epistemic objectivity does not require ontological objectivity. If it did, the social sciences would be impossible. Now with all that by way of preliminaries, we can state the basic logical structure of human societies. Here goes.

\section{The Logical Structure of Society}

Human societies have a logical structure, because human attitudes are constitutive of the social reality in question and those attitudes have propositional contents with logical relations. Our problem is to expose those relations. Now it might seem that this is too daunting a task. Human societies are immensely complex and immensely various. If there is one thing we know from the cultural anthropology of the past century, it is that there is an enormous variety of different modes of social existence. The assumption I will be making, and will try to justify, is that even though there is an enormous variety, the principles 
that underlie the constitution of social reality are rather few in number. What you discover when you go behind the surface phenomena of social reality is a relatively simple underlying logical structure even though the manifestations in actual social reality in political parties, social events, and economic transactions are immensely complicated. The analogy with the natural sciences is obvious. There is an enormous difference in the physical appearance of a bonfire and a rusty shovel, but the underlying principle in each case is exactly the same: oxidization. Similarly, there are enormous differences between baseball games, twenty dollar bills, and national elections, but the underlying logical structure is the same. All three consist of the imposition by collective intentionality of status functions, a point I will shortly explain in more detail.

To describe the basic structure of social-institutional reality, we need exactly three primitives, collective intentionality, the assignment of function, and constitutive rules and procedures. (Here I am going to be very brief because I am repeating things I have said elsewhere.)

First, human beings have a remarkable capacity, which many other species also have, and that is to engage in cooperative behavior and sharing of attitudes with con-specifics. Human beings can collaborate in a number of ways, and one has only to observe any typical human interaction to see this. Two people carrying on a conversation, an orchestra playing a symphony, and two teams playing football, are all examples of cooperative behavior. I want to introduce a technical term for this. I call this collective intentionality. I will explain this term. "Intentionality» is the word philosophers use to describe that feature of minds by which mental states are directed at or about objects and states of affairs in the world. Thus, for example, if I have a belief it must be a belief that such and such is the case; if I have a desire it must be a desire that such and such should be the case. Intentionality, in this technical sense, includes not only intending in the ordinary sense, in which I might intend to go to the movies, but also beliefs, hopes, desires, emotions, perceptions, and lots of others. In addition to individual intentionality, which is described in the first-person singular forms such as "I desire», «I believe», "I intend,» there is also collective intentionality, which is described in the form, "we believe» "we desire» "we intend.»

Collective intentional action is especially important in any theory of society. In such cases, I am doing something only as part of our doing something. For example, I am playing the violin part as part of our playing the symphony. I am pitching the ball as part of our playing a baseball game. Collective intentionality is the intentionality that is shared by different people, and just as there can be shared intentions to do things, so there can be shared beliefs and shared desires. The church congregation, for example, reciting the Nicene Creed, is expressing a shared belief, a common faith.

It is common in social philosophy, and perhaps in the social sciences as well, to use the notion of «intersubjectivity». I have never seen a clear explanation of the concept of intersubjectivity, and I will have no use for the notion. But I will use «collective intentionality» to try to describe the intentionalistic com- 
ponent of society; and I suspect that if intersubjectivity is a legitimate notion at all, it must amount to collective intentionality. I am confident that collective intentionality is a genuine biological phenomenon, and though it is complex, it is not mysterious or inexplicable. I have tried to describe some of the complexities elsewhere ${ }^{3}$. Collective intentionality is the psychological presupposition of all social reality and, indeed, I define a social fact as any fact involving collective intentionality of two or more human or animal agents. So on this definition, both a wolf pack hunting together and a supreme court making a decision are cases of collective intentionality and thus cases of social facts. My main problem in this article is to explain how such institutional social phenomena as the Supreme Court making a decision goes beyond the social ontology present in social animals. The interesting problem arises not with social facts but with such institutional facts as those involving money, governments, political parties and economic transactions. Institutional facts are a subclass of social facts.

The second primitive notion we need is that of the assignment of function. Humans, and some animals, have the capacity to assign functions to objects, where the object does not have the function intrinsically but only in virtue of the collective assignment. All functions are observer relative. Something has a function only relative to the attitudes of humans or other animals. We are blinded to this by the fact that in biology we frequently discover functions in nature. But when we discover, for example, that the function of the heart is to pump blood, we can only make that discovery within a presupposed teleology. It is because we value life and survival that we say the function of the heart is to pump blood. If we thought the most important thing in the universe was to glorify god by making a thumping noise, then the function of the heart would be to make a thumping noise. If we thought death and extinction were valuable above all else, then hearts would be dysfunctional and cancer would perform an important function. Lots of people disagree with me that all functions are observer relative, but the argument that seems to me conclusive is that the notion of function contains a normative component not contained in the notion of cause. Roughly speaking, functions are causes that serve a purpose. Where do the purposes come from? In any case it is not essential for the main argument of this article that functions are observer relative, though I note it in passing.

So far, then, we have collective intentionality and the assignment of function. It is easy to see how these can be combined. If one person can use a stump as a chair, a group of people can use a $\log$ as a bench. The collective intentionality enables the collective assignment of a function.

But it is the next move which is the distinguishing mark that separates humans from other species. Sometimes the collective assignment of function is imposed on a person or an object where the function is not performed in 
virtue of the physical features of the person or the object, but rather, in virtue of the fact that the collective intentionality assigns a certain status to that person or object and that status enables the person or object to perform a function which could not be performed without the collective acceptance of that status. An obvious example is money. The piece of paper in my hand, unlike the knife in my pocket, does indeed perform a function, but it performs the function not in virtue of its physical structure but in virtue of collective attitudes. The knife has a physical structure that enables it to cut and perform other knife-like functions, but money has no such physical structure. The physical structure is more or less irrelevant, provided only that it meets certain general conditions (such as being easy to recognize as money, easy to transport, hard to counterfeit, etc.). I like to illustrate the move from the assignment of functions to what I call status functions with a parable. Suppose a community builds a wall around its dwellings. The wall now has a collectively assigned function, which function it can perform in virtue of its structure. But suppose the wall gradually decays until the only thing that is left is a line of stones. But suppose that the people continue to recognize the line of stones as a boundary, they continue to accept that they are not supposed to cross. The line now performs the function that the wall once performed, but it performs the function not in virtue of its physical structure but in virtue of the collective acceptance that the line of stones now has a certain status and with that status a function which can only be performed in virtue of the collective acceptance of that status. I want this to sound rather harmless and innocuous, but I think that in fact it is the decisive move that distinguishes humans from other animals. It is this move whereby we create status functions that marks the difference between social reality in general and what I will call institutional reality. Human institutions are matters of status functions.

I have tried to state the logical form of the assignment of a status function when it becomes regular, and thus a matter of a rule, as that of the constitutive rule of the form, $\mathrm{X}$ counts as $\mathrm{Y}$, or more commonly, $X$ counts as $Y$ in context $C$. Thus, such and such counts as a twenty dollar bill in our society. George W. Bush counts as President of the United States. Such and such a move in chess counts as a legal knight move. Such and such a position counts as a check, and such and such a form of check counts as checkmate. All of these are of the form $\mathrm{X}$ counts as $\mathrm{Y}$ in context $\mathrm{C}$. Now, you might think that if that is all there is to human institutional reality, if that is what distinguishes us from the lower beasts, then it does not seem like much to go on. But it has two formal properties that are truly remarkable. First, it can iterate upwards indefinitely. Thus, making such and such noises counts as uttering a sentence of English, and uttering such and such a sentence of English counts as making a promise, and uttering such and such a promise counts as undertaking a contract. Notice what is going on in these cases. At the bottom level, $X_{1}$ counts as $Y_{1}$, but at one level up, $Y_{1}=X_{2}$ counts as $Y_{2}$. And $Y_{2}=X_{3}$ counts as $Y_{3}$ and so on upward indefinitely. Furthermore, the structure not only iterates upward, but it expands laterally also indefinitely. We never just have one institutional fact but we have 
a series of interlocking institutional facts. Thus, I do not just have money, but I have money in my bank account at a certain financial institution, it is placed there by my employer, The University of California, and I use it to pay my credit card debts and my state and federal income taxes. All of those are institutional notions, and the example illustrates the way institutions interlock with each other. To repeat, you do not just have one institutional fact, you have a series of interlocking institutional facts, and thus, you have a series of interlocking institutions.

But still, you might say, what is the importance of all this? Who cares if we assign all these status functions? The answer is that status functions are the vehicles of power in society. The remarkable thing is this: we accept the status functions and in so accepting, we accept a series of obligations, rights, responsibilities, duties, entitlements, authorizations, permissions, requirements, etc. As a shorthand, I call these deontic powers. Thus, for example, if someone is my wife, if a piece of property is my property, if I have received a parking ticket, if I am a professor at the University of California, all of these are matters of deontic powers both positive and negative. Thus, if it is my property, I have a certain authority over it, and I am required by law to pay the taxes on it. If I have received a parking ticket, I have an obligation to pay the fine. There is nothing like this in the animal kingdom. What we have in society is a set of deontic power relations. But again, one might ask the question, why should we care about these deontic power relations? Who gives a damn about my rights, duties and obligations? The answer is important: What we are discussing here are reasons for action, and to recognize something as a right, duty, obligation, requirement, etc. is to recognize a reason for action. Furthermore, it is a specific kind of reason for action that is absolutely essential to human society and which, as far as I can tell, does not exist in the animal kingdom: These deontic structures make possible desire-independent reasons for action.

If I have a piece of property, and other people recognize that it is my property, then they have desire-independent reasons for not violating my property rights, and so on with rights generally. Contrast the territoriality of animals with the property rights of human societies. There are lots of differences but for the purpose of this discussion, the crucial point is that, as far as we can tell, animals lack a deontology.

So again, it is this combination, status functions, deontic powers, and desire-independent reasons for actions that gives us the specific human forms of socialization that enable us to distinguish human beings from other social animals, even from other primates. Now, we ought to allow ourselves to be astounded by this. The other primates are genetically very close to us. All the same, there is an enormous difference, or, rather, there is a series of enormous differences between the ontology of human social life and that of animals ${ }^{4}$. 
The most fundamental difference between us and other animals, and this point has been made by a number of philosophers, perhaps most famously Descartes, is that we have a language and other animals do not. It is, however, seldom made clear exactly what is involved in having a language. If you read standard socio-biologists such as Wilson ${ }^{5}$ or Barash ${ }^{6}$ you get the impression that many species of animals have signaling systems, but that humans are special in that we have a more elaborate signaling system than other animals. I think this is an inadequate conception of language. This is not the place for me to develop my entire theory of speech acts, but let me say just this much. The essential thing about human beings is that language gives them the capacity to represent. Furthermore, they can represent not only what is the case but what was the case, what will be the case and what they would like to be the case. Even more spectacularly, they can lie. They can represent something as being the case even though they believe that it is not the case.

We can now state with a little bit more precision exactly what is special about language in the constitution of institutional reality. Institutional reality can only exist insofar as it is represented as existing. Something can be money, a football game, a piece of private property, a marriage or a government only insofar as it is represented as such. In order for something to be any of these phenomena, it has to be thought of in a certain way, and these thoughts will represent it in a certain way. But the representation of these institutional facts always requires a language. Now, why is that? Why could not one just think that such and such is a government or such and such is a football game? The answer is, there is no phenomenon there other than the brute facts and their representation as having an institutional status. There is nothing in the bare physical facts that would provide the semantic content which we would have to be able to think in order to think that such and such was a government or a football game. Let me illustrate this with an example. My dog can see a person carry a ball across a line; but what he cannot see is the person scoring a touchdown. Now, why not? Is his vision not good enough? Does he need glasses? Suppose we decided that we were going to train the dog to see touchdowns. How would we go about it? We might train him to bark when he sees a man crossing a line while carrying a ball, but in order to see a man scoring a touchdown, he has to be able to represent something more than these physical facts. The physical facts that the dog sees and the physical facts that I see are exactly the same. What I have, that the dog does not have, is the capacity to represent those facts in a certain way, to represent them as existing at the higher level, to represent them as the $\mathrm{Y}$ term, in the $\mathrm{X}$ counts as $\mathrm{Y}$ formula. Now, this is the secret by which human beings can create an institutional reality and other animals cannot. Human beings have the capacity for seeing and thinking at a double level. We can both see the piece of paper and the dollar bill. We can both

5. Wilson (1975).

6. Barash (1977). 
see the man carry the ball across the line and see the man score a touchdown. At first sight, this looks like a familiar case of seeing as. We see the figure now as a duck, now as a rabbit. But what is special about human beings is that they have the capacity, which the dog does not have, to see and think an institutional reality, but that is impossible just on the basis of the sheer physical facts because there is nothing in the physical facts to give the semantic content either to the thought or to the perception. The light waves striking my eyes when the man crossed the goal line and the light waves striking the dog's eyes are the same, but I literally saw the man score a touchdown, and the dog did not literally see that. In such cases, institutional reality so infects our perceptual and other forms of cognitive apparatus that the immediate processing of perceptual inputs is already done at the institutional level. Just as I can literally see a man score a touchdown, so I can literally see a man pay for groceries in a supermarket, and I can literally see my neighbor voting in an election.

Let us explore these ideas by going through some of the steps in which language is involved in the constitution of institutional reality.

We have the capacity to count things as having a certain status, and in virtue of the collective acceptance of that status, they can perform functions that they could not perform without that collective acceptance. The form of the collective acceptance has to be in the broadest sense linguistic or symbolic because there is nothing else there to mark the level of status function. There is nothing to the line and the man and the ball that counts as a touchdown, except insofar as we are prepared to count the man with the ball crossing the line as the scoring of a touchdown. We might put these points in the most general form by saying that language performs at least the following four functions in the constitution of institutional facts.

First, the fact can only exist insofar as it is represented as existing and the form of those representations is in the broadest sense linguistic. I have to say "in the broadest sense,» because I do not mean to imply that full-blown natural languages with relative clauses, iterated modal operators, and quantificational scope ambiguities are essential to the constitution of institutional reality. I do not believe they are. Rather, I believe that unless an animal can symbolize something as having a status, which it does not have in virtue of its physical structure, then the animal cannot have institutional facts, and that those institutional facts require some form of symbolization - what I am calling language in the broad sense. The symbolization has to carry the deontic powers, because there is nothing in the sheer physical facts that carries the deontology by itself.

Secondly, and this is really a consequence of the first point, the forms of the status function in question are almost invariably matters of deontic powers. They are matters of rights, duties, obligations, responsibilities, etc. Now, animals cannot recognize deontic powers because without having some linguistic means of representation they cannot represent them. Let me state this point with as much precision as I can. Animal groups can have an alpha male and an alpha female, and other members of the group can make the proper 
responses to the alpha male and the alpha female, but this hierarchy is not established by the undertaking or imposition of such things are rights and obligations. What the animals do not have is the deontology, the obligations, requirements, duties, etc. that go with the recognition of the higher status. For those obligations, requirements, and duties to exist, they have to be represented in some linguistic or symbolic form. Again, when a dog is trained to obey commands, he is just taught to respond automatically to certain specific words or other signals.

(By the way, I frequently make remarks about animal capacities. I do not think we know enough about animal capacities to be completely confident in the attributions we make especially to the primates. But, and this is the point, if it should turn out that some of the primates are on our side of the divide rather than on the side of the other animals, in the sense that they have deontic powers and deontic relationships, then so much the better for them. In this article, I am not making a plea for the superiority of our species, rather, I am trying to mark a conceptual distinction, and I assume on the basis of what little I know, that where deontology is concerned we are on one side and other animals are on the other side of the dividing line. If it turns out that some of them are on our side, I have no problem with that.)

Third, the deontology has another peculiar feature. Namely, it can continue to exist after its initial creation and indeed even after all the participants involved have stopped thinking about the initial creation. I make a promise today to do something for you next week, and that obligation continues even when we are all sound asleep. Now, that can only be the case if that obligation is represented by some linguistic means. In general, one can say this: No language, no deontology. Human societies require a deontology, and the only way they can do this is by having language.

Fourth, a crucial function of language is in the recognition of the institution as such. It is not merely particular cases within the institution, that this is my property, that that was a football game, but rather, in order that this should be a case of property or that a case of a football game, one has to recognize an institution of property and football games. Where institutional reality is concerned, the particular instances typically exist as such because they are instances of a general institutional phenomenon. Thus, in order for me to own a particular item of property, or to have a particular dollar bill, there has to be a general institution of private property and money. Exceptions to this are cases where an institution is being created de novo. But these general institutions, in which the particular instances find their mode of existence, can only exist insofar as they are recognized and that recognition has to be symbolic, linguistic in the most general sense.

\section{Further Developments in the Theory of Social Ontology}

I want now to discuss some of the further developments in the theory of institutional reality since the publication of The Construction of Social Reality. I want 
to mention two such developments. First, in the original statement of the theory, I pointed out that in order for status functions to be recognized, there typically have to be some sort of status indicators, because there is nothing in the man or the object itself that will indicate its status, since the status is only there by collective acceptance or recognition. Thus, we have policemen's uniforms, wedding rings, marriage certificates and passports, all of which are status indicators. Many societies find that they cannot exist without status indicators, as, for example, the proliferation of identity cards and driver's licenses will attest. However, Hernando De Soto ${ }^{7}$ pointed out an interesting fact. Sometimes the status indicators acquire a kind of life of their own. How is this so? Well, he points out that in many underdeveloped countries, many people own land, but because there are no property deeds, because the owners of the property do not have title deeds to the property, they are, in effect, what we would call squatters, they do not have status indicators. This has two consequences of enormous social importance. First, they cannot be taxed by the governing authorities because they are not legally the holders of the property, but secondly and even more importantly, they cannot use the property as capital. Normally, in order for a society to develop, the owners of property have to be able to go to the bank and get loans against their property in order to use the money to make investments. But in countries like, for example, Egypt, it is impossible for the vast amount of private property to be used as collateral for investments because so much of this property is held without the benefit of a property deed. The owners of the property are in effect squatters, in the sense that they do not legally own the property, though they live in a society where their status function is acknowledged and generally recognized and hence, on my account, continues to exist and generate deontic powers. But the deontic powers stop at the point where the larger society requires some official proof of the status functions. Thus without official documentation they lack full deontic powers.

A second and equally important development was pointed out to me by Barry Smith. Smith pointed out that there are some institutions that have what he calls «free-standing Y terms» where you can have a status function, but there is no physical object on which the status function is imposed. A fascinating case is corporations. The laws of incorporation in a state such as California enable a status function to be constructed so to speak out of thin air. Thus, by a kind of performative declaration, the corporation comes into existence, but there need be no physical object which is the corporation. The corporation has to have a mailing address and a list of officers and stock holders and so on, but it does not have to be a physical object. This is a case where the performative utterance «such and such counts as the creation of a corporation" does indeed create a corporation, but there is no physical object other than the relationship among certain people on which the status function is imposed. There is indeed a "counts as Y" but there is no $\mathrm{X}$ which counts as $\mathrm{Y}$. 
An even more spectacular example is money. The paradox of my account is that money was my favorite example of the «X counts as $\mathrm{Y}$ » formula, but I was operating on the assumption that currency was somehow or other essential to money. Further reflection makes it clear to me that it is not. You can easily imagine a society that has money without having any currency at all. And, indeed, we seem to be evolving in something like this direction with the use of debit cards. All you need to have money is a system of recorded numerical values whereby each person (or corporation, organization, etc.) has assigned to him or her a numerical figure which tells at any given point the amount of money they have, and they can then use this money to buy things by altering their numerical value in favor of the seller, whereby they acquire a lower numerical value and the seller acquires a higher numerical value. Money is typically redeemable in cash, in the form or currency, but currency is not essential to the existence or functioning of money.

It is tempting in such cases to think that the representation of the money in the form of magnetic traces on computer disks or entries in ledgers have become money. After all, manipulation of the numerals in the ledgers or the magnetic traces on the computer disks can constitute buying and selling, paying and receiving, so why are they not money? Even in such cases, it is important to distinguish between the representation of the institutional phenomenon and the institutional phenomena represented. You can see this if you consider the case of chess. Just as currency is not essential to the functioning of money, so physical chess pieces are not essential to the playing of chess. In the case of blindfold chess, you play the game entirely using representations of the chess pieces in the forms of a symbolism that defines the pieces and their positions on the board. But neither the board nor the pieces as physical objects are essential. All that is essential is that there should be a set of formal relationships that are capable of being represented symbolically. The symbols that we use do not, then, become chess pieces, though they become functionally equivalent to chess pieces in that the manipulation of the symbols is functionally equivalent to the movement of the chess pieces. Exactly analogously, the existence of physical objects of currency, coins and bills, is not essential to the functioning of money. All that is essential is that there should be a set of numerical values attaching to individuals and a set of formal relations between these whereby they can use their numerical assignment to buy things from other individuals, pay their debts, etc.

How can such things function if there is no physical object on which the status function is imposed? The answer is that status functions are, in general, matters of deontic power, and in these cases, the deontic power goes directly to the individuals in question. So my possession of a queen in the game of chess is not a matter of my having my grubby hands on a physical object, it is rather a matter of my having certain powers of movement within a formal system (and the formal system is "the board,» though it need not be a physical board) relative to other pieces. Similarly, my having a thousand dollars is not a matter of my having a wad of bills in my hand but my having certain deon- 
tic powers. I now have the right, i.e. the power, to buy things, which I would not have if I did not have the money. In such cases, the real bearer of the deontology is the participant in the economic transactions and the player in game. The physical objects of chess pieces and dollar bills are just markers for the amount of deontic power that the players have.

In the early part of The Construction of Social Reality, I said that the basic form of the institutional fact was $\mathrm{X}$ counts as $\mathrm{Y}$ in $\mathrm{C}$ and that this was a form of the constitutive rule that enables us to create institutional facts. But a later formulation I gave in the book gives us a much more general account. I said that the basic power creation operator in society is We accept ( $S$ has power ( $S$ does $A)$ ) and that we could think of the various forms of power as essentially Boolean operations on this basic structure, so, for example, to have an obligation is to have a negative power. What then, exactly, is the relationship between the two formulae $X$ counts as $Y$ in $C$ and We accept ( $S$ has power ( $S$ does $A)$ )? The answer is that, of course, we do not just accept that somebody has power, but we accept that they have power in virtue of their institutional status. For example, satisfying certain conditions makes someone President of the United States. This is an example of the $X$ counts as $Y$ in $C$ formula. But once we accept that someone is President of the United States, then we accept that he has the power to do certain things. He has the positive power to command the armed forces, and he has the negative power, i.e. the obligation, to deliver a state of the union address. He has the right to command the armed forces, and he has the duty to deliver the address. In this case we accept that $S$ has power ( $S$ does $A$ ) because $\mathrm{S}=\mathrm{X}$, and we have already accepted that $\mathrm{X}$ counts as $\mathrm{Y}$, and the $\mathrm{Y}$ status function carries with it the acknowledged deontic powers.

Continuing with the example of the corporation, we can say that so and so counts as the president of the corporation and such and such people count as the stockholders. This is an example of the $X$ counts as $Y$ in $C$ formulation, but, of course, the whole point of doing that is to give them powers, duties, rights, responsibilities, etc. They then instantiate the We accept ( $S$ has power( $S$ does A)) formula. But to repeat a point made earlier, the corporation itself is not identical with any physical object or any person or set of persons. The corporation is, so to speak, created out of nothing. The president, is president of the corporation, but he is not identical with the corporation. The reasons for doing this are famous. By creating a so-called "fictitious person» we can create an entity that is capable of entering into contractual relationships and capable of buying and selling, making a profit and incurring debts, for which it is liable. But the officers and stockholders, are not personally liable for the debts of the corporation. This is an important breakthrough in human thought. So what amounts to the corporation when we set it up? It is not that there is an $\mathrm{X}$ that counts as the corporation but, rather, that there is a group of people involved in legal relationships, thus, so and so counts as the president of the corporation, so and so counts as a stockholder in the corporation, etc., but there is nothing that need count as the corporation itself, because one of the points of setting up the corporation was to create a set of power relationships without 
having to have the accompanying liabilities that typically go with those power relationships when they assigned to actual human individuals.

I regard the invention of the idea of the limited liability corporation, like the invention of double-entry book-keeping, universities, museums, and money, as one of the truly great advances in human civilization. Such inventions are less famous than the invention of steam engines and airplanes, but they are of comparable importance. It is not at all necessary that there should be such things as corporations or universities, but it is clear that without them human civilization would be impoverished and limited.

It might seem paradoxical that I talk about institutional reasons for action as «desire independent reasons for action» because, of course, many of these are precisely foci of very powerful human desires. What is more a field for human desire than money? Or political power? I think this question raises a deep issue: By creating institutional reality, we increase human power enormously. By creating private property, governments, marriages, stock markets and universities, we increase the human capacity for action prodigiously. But the possibility of having and satisfying desires within these institutional structures - for example, the desire to get rich, to become president, to get a $\mathrm{PhD}$, to get tenure- all presuppose that there is a recognition of the deontic relationships. Without the recognition, acknowledgment, and acceptance of the deontic relationships, your power is not worth a damn. It is only worthwhile to have money or a university degree or to be President of the United States if other people recognize your having this status, and they recognize that status as giving them desire independent reasons for behaving in a certain way. The general point is very clear: the creation of the general field of desire-based reasons for action presupposed the acceptance of a system of desire independent reasons for action. This is true both of the immediate beneficiaries of the power relationships, the person with the money or the person who has won the election, and of the other participants in the institution.

\section{How Many Kinds of Institutional Facts Are There?}

I still do not have a taxonomy of status functions that I find satisfactory. I think it is rather easy and, indeed, rather uninteresting, to do a taxonomy of different kinds of institutions because one would naturally classify institutions according to their purposes and subject matters, educational institutions, governmental institutions, financial institutions, social institutions, etc. A much more interesting and profound question is: How many kinds of institutional facts are there? This is the question that gets at a taxonomy of status functions. I am inclined to think that a basic division occurs between those status functions that accrue to people where the physical properties are essential to the status function and those where they are not, between being a licensed driver or a surgeon or a certified public accountant on the one hand and being money, or a corporation on the other. In the case where you are a licensed driver or you are authorized to perform surgery, you have to have certain abilities 
independent of the authorization. The authorization allows you to do something that you are able to do anyway, as far as your sheer abilities are concerned. But when it comes to money, that is not the case. The piece of paper or, for that matter, the magnetic trace on the computer disk in your bank, do not have any powers in virtue of their physical structure. It is, rather, the collective acceptance that creates the power in the first place.

If we were going to attempt a taxonomy of institutions, I think the right way to go about it would be to do a taxonomy of institutional powers, because the whole purpose of having institutions is to create and distribute human power, specifically deontic power. The first thing we would have to recognize are those powers that have to do with certifying or authorizing people to do things, after ascertaining that they are competent to do them. This applies to certified public accountants, lawyers, doctors, ski instructors, licensed drivers, credentialed teachers, and also, of course, to tests for roadworthiness of vehicles, seaworthiness of ships, and to safety inspections of buildings and bridges. Such authorization allows the functioning of a pre-existing fitness and capacity.

This distinction is already prefigured in the theory of speech acts. I distinguish between declarations that simply create a state of affairs by declaring it to exist, such as a declaration of war, and what I call assertive declarations, where there is first a finding of fact and then the assignment of a status. For example if it is found that the defendant did the act alleged against him, then he is pronounced "guilty as charged,» an assertive declaration. Analogously with some status functions. First there is an examination of the facts. Can the applicant actually drive a car? Then on the basis of an affirmative answer, he is assigned the status function of «licensed driver».

We will also need to distinguish certifications from authorizations. Thus, for example, a driving test will certify me as a competent driver and the issuance of a driving license or driving permit will authorize me to drive, for example, in the state of California. Typically, authorizations require prior certifications, but not all certifications are authorizations. Thus, for example, if you receive a bachelor's degree from an American university, you are certified as having met the criteria for the degree, but what does the degree now authorize you to do? Well, it authorizes nothing specific in the way that being a certified public accountant or having your driver's license authorizes you to do something specific. Nonetheless, the certification is important because there are an indefinite range of authorizations now open. There are, for example, all sorts of employment for which a bachelor's degree is a pre-requisite.

A second category would include what we might think of as institutional power as such. Thus, for example, the chairman of the department, the President of the United States, a congress person, are given powers which they would not be able to exercise without the enabling status that gives them the power.

Where sheer institutional power is concerned, it seems to me we will need to make a distinction between positive and negative powers. The chief of police, the president of the corporation, and the commander of the army, all have positive powers. The prisoner of war, the convicted criminal, and the driver 
in receipt of a traffic citation all have negative powers. Within the category of negative powers, we will also need to distinguish punishments from taxes. Owing a thousand dollars in taxes and being fined a thousand dollars are quite distinct status functions, even though the upshot is exactly the same in both case: I have to pay a thousand dollars to the authorities. The mirror image of this on the positive side would be the distinction between salaries and prizes. The opposite of the tax is the salary that I receive. The opposite of the punishment is the prize or the award. Thus, the person who makes a million dollars in the stock market and the person who receives the prize of a million dollars are both in receipt of a million dollars. But the status functions are quite different.

\section{Conceptual Analysis and Empirical Data}

It seems to me quite likely that some people in cultural anthropology will feel that I am making generalizations on the basis of what seem to be very limited data. The data that I am familiar with are, for the most part, derived from cultures that I happen to inhabit or have inhabited, and some that I have read about. What makes me think that this provides us with a general theory of social ontology? To answer this question, I need to make a distinction between empirical generalization and conceptual analysis. There is no sharp dividing line between the two, but the nature of the investigation that I am conducting here is one of taking certain empirical facts and trying to uncover underlying logical structures. I do not discover status functions just by examining the data, but by uncovering the logical structure of the data I am familiar with.

The analogy with the theory of speech acts is illuminating. When I published a taxonomy of the five basic types of speech acts ${ }^{8}$, one anthropologist objected that in the tribe that she studied, they did not make many promises, and, anyway, how did I think I could get away with making such a general claim on the basis of such limited data? ${ }^{\text {B }}$ But the answer, of course, is that I was not offering a general empirical hypothesis but a conceptual analysis. These are the possible types of speech acts given to us by the nature of human language. The fact that some tribe does not have promising is no more relevant than the fact that there are no tigers at the South Pole is relevant to a taxonomy of animal types. I am discussing the logical structure of language and getting the categorization of possible types of speech acts. In this investigation, I am

8. Searle (1979).

9. Rosaldo (1982). When this article first appeared I did not respond to it because I thought she had missed the point of my analysis. She thought I was making an empirical generalization to the effect that all cultures had certain types of speech acts, when I was in fact presenting a conceptual analysis of what it is possible to do with language. When tracking down the reference to her article on the web I discovered to my amazement that it is still used in anthropology courses, so the distinction is perhaps worth emphasizing here. 
examining the logical structure of human civilization and trying to get at the basic structure of status functions. But, again, that forces the question back one stage. Well, what makes me think that these status functions I discover in our civilization are likely to be pervasive? And the answer, of course, is that they are not. Not all communities have driver's licenses, for example. But, and this is the crucial point, the logical structure of the status function, I believe, is pervasive, and I now want to state why: All human societies have a language, and in that language there are certain limited possibilities for performing speech acts having to do with the very nature of meaning and the nature of speech acts (I have explored all this in some detail elsewhere ${ }^{10}$ ). Now, that already gives you a set of deontic powers. That gives you the rights, duties and obligations that go with making a statement, making a promise or making a request, so the basic structure is already present in the theory of speech acts. Now, it is very hard for me to imagine a culture that did not have any rights, duties and obligations beyond those that derive from the performance of speech acts, but even if there were such a culture, it is, so to speak, standing on the threshold of having institutional reality because once, in any language whatever, that somebody is in a position to say "This is mine» or "He is the boss» you have already embarked on the creation of non-linguistic status functions even though, of course, the language, for reasons that I have tried to make clear, is constitutive of those status functions. The thesis advanced here, then, is not an anthropological empirical hypothesis. I am not hypothesizing that all societies have such and such logical structures. Rather, I am analyzing the logical structures, and any society that has what we would consider to be the deontology of even a minimal civilization will have to have something like these structures. Now, of course, even an a priori conceptual argument like that would be subject to empirical refutations if you could show me a society that had what were intuitively institutional structures but had nothing like the sorts of structures that I describe. But if an anthropologist tells me that in the tribe she studies they don't worry too much about obligations, and if she thinks that is an objection to the analysis, she will have missed the point.

\section{Different Kinds of «Institutions»}

I have not been attempting to analyze the ordinary use of the word «institution.» I do not much care if my account of institutional reality and institutional facts matches that ordinary usage. I am much more interested in getting at the underlying glue that holds human societies together. But let us consider some other sorts of things that might be thought of as institutions.

I have said that the fact that I am an American citizen is an institutional fact, but how about the fact that today is the $15^{\text {th }}$ of July, 2004? Is that an institutional fact? What does the question ask? At least this much. Does iden- 
tifying something as $15^{\text {th }}$ of July 2004 collectively assign a status function that carries with it a deontology? So construed the answer is no. In my culture there is no deontology carried by the fact that today is July $15^{\text {th }}$. In that respect, "July $15^{\text {th }}$ 2004» differs from Christmas Day, Thanksgiving, or, in France, July $14^{\text {th }}$. Each of these carries a deontology. If it is Christmas Day, for example, I am entitled to a day off, and collective intentionality in my community supports me in this entitlement. We could easily imagine a subgroup for which being July 15 th was an institutional fact, but I am currently not in such a subgroup.

I think there is a sense of the word «institution» in which the Christian calendar is a kind of institution, but it is not the kind of institution that I am attempting to analyze. Similarly with other verbal systems. Different societies have different color vocabularies, but that does not make the fact that the cloth in front me is magenta into an institutional fact. Similarly remarks could be made about systems of weights and measurements. The fact that I weigh 160 pounds is the same fact as the fact that I weigh 72 kilos even though this same fact can be stated using different systems of measuring weights.

More interesting to me are those cases where the facts in question are on the margin of being institutional. I think that the fact that someone is my friend is an institutional fact because friendship carries obligations, rights and responsibilities. But how about the fact that someone is a drunk, a nerd, an intellectual or an underachiever? Are these institutional concepts and are the corresponding terms institutional facts? Not as I am using these expressions, because there is no collectively recognized deontology that goes with these. Of course, if the law establishes criteria under which somebody is a certified drunk and imposes penalties as well as compensation for this status, then being a drunk becomes a status function. X counts as Y. And, again, I might personally feel that as an intellectual, I have certain sorts of obligations, but this is still not yet an institutional phenomenon unless there is some collective recognition of these obligations. When I pointed out in a lecture that being a nerd was not a status function, one of my students told me that in his high school it definitely was, because as the class nerd he was expected to help other students with their homework. He was under certain sorts of collectively recognized obligations.

Another sort of «institution» that I am not attempting to describe is massive forms of human practices around certain subject matters that do not as such carry a deontology. So, for example, there are series of practices that go with what we call «science» or «religion» or «education.» Does that make science, religion and education into institutions? Well, we are using institution as a technical term anyway, and it is open to us if we want to call these institutions, but I think it is very important that we not confuse science, education and religion with such things as money, property, government and marriage. Within such gross human practices as science, religion and educations there are, indeed, institutions. Thus, for example, the National Science Foundation is an institution, as is the University of California or the Roman Catholic Church. As I said before, I do not much care whether or not we want to use the 
word «institution» for both sorts of practices, but the important underlying idea is crucial to emphasize: we need to mark those facts that carry a deontology because they are the glue that holds society together.

\section{References}

BARASH, David P. (1977). Sociobiology and Behavior. Amsterdam: Elsevier.

DE SOTO, Hernando (2003). The Mystery of Capital: Why Capitalism Triumphs in the West and Fails Everywhere Else. New York: Basic Books.

Kummer, Hans (1971). Primate Societies: Group Techniques of Ecological Adaptation (Worlds of Man). Chicago: Aldine-Atherton.

RosAldo, Michelle (1982). "The Things We Do With Words: Llongot, Speech Acts, and Speech Act Theory in Philosophy». Language and Society, vol. 11, p. 203-237.

SEARLE, John R. (1979). "A Taxonomy of Illocutionary Acts». In: Expression and Meaning. Studies in the Theory of Speech Acts. Cambridge: Cambridge University Press, p. 1-29.

- (1983). Intentionality: An Essay in the Philosophy of Mind. Cambridge: Cambridge University Press.

- (1990). «Collective Intentions and Actions». In CoHEN, P.; Morgan, J.; POLLACK, A. (eds.). Intentions in Communication. Cambridge, Massachusetts: MIT Press. (Reprinted in: John R. Searle. Consciousness and Language. Cambridge University Press, 2002).

- (1995). The Construction of Social Reality. New York: Free Press.

WiLsOn, Edward O. (1975). Sociobiology: A New Synthesis. Cambridge, MA: Harvard

University Press. 